\title{
Moko de plátano y su relación con propiedades físicas y químicas en suelos del departamento de Quindío, Colombia
}

\begin{abstract}
Moko of plantain and its relationship with physical and chemical properties in soils of the department of Quindio, Colombia
\end{abstract}
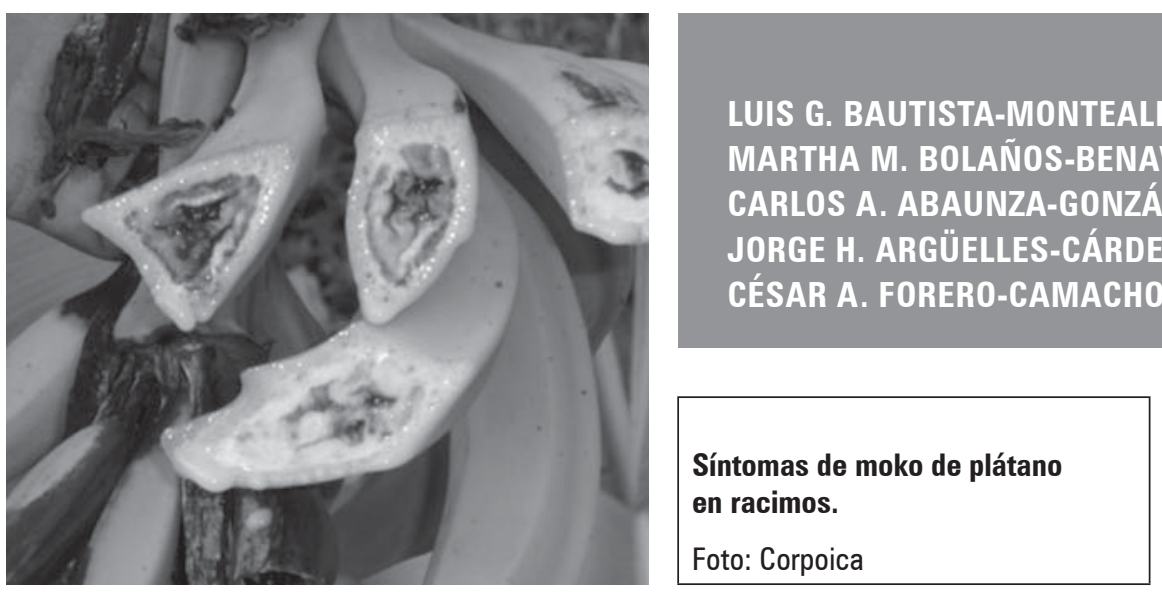

\section{RESUMEN}

El cultivo de plátano en el departamento de Quindío (Colombia), ha sido por tradición uno de los productos de mayor importancia en la economía de la región. Este cubre más de $50 \%$ del área agrícola y contribuye con $7,2 \%$ de la producción nacional. La bacteria Ralstonia solanacearum, agente causal de la enfermedad del moko de plátano, es el problema fitosanitario más importante en el departamento, debido al incremento de $17 \%$ en el número de municipios afectados a partir del año 2002. Con el fin de contribuir con el manejo de este problema, se exploró la relación entre la incidencia de la enfermedad y variables relacionadas con propiedades físicas y químicas del suelo, así como el uso del suelo y la ubicación altitudinal. Se estudiaron 269 fincas, empleando un diseño de muestreo estratificado con afijación proporcional al área sembrada. Se analizaron suelos y tejidos foliares, así como los síntomas de la enfermedad. Se ajustó un modelo de regresión logística para establecer el efecto de las variables sobre la probabilidad de ocurrencia de la enfermedad. De acuerdo a los resultados del modelo, mediante el software ArcGis 9.3 (ESRI $\left.{ }^{\circledR}\right)$, se interpolaron los puntos en georreferenciados utilizando la técnica de distancia inversa ponderada. En $52 \%$ de los predios evaluados, se detectó la enfermedad, y se encontró una correlación positiva y significativa entre la incidencia de la enfermedad, la conductividad hidráulica y la saturación de potasio en suelo; y negativa y significativa con la altitud, concentración de cobre foliar y presencia de cultivos asociados.

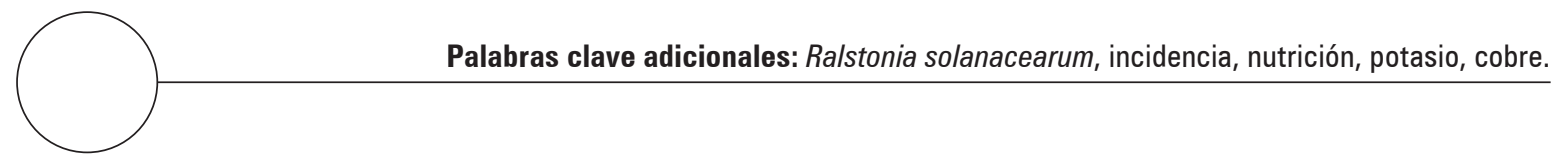

\footnotetext{
Corporación Colombiana de Investigación Agropecuaria (Corpoica), C.I. Tibaitatá, Mosquera (Colombia).
}

2 Autor para correspondencia.mmbolanos@corpoica.org.co 


\section{ABSTRACT}

In the department of Quindío (Colombia), the plantain crops have traditionally been the most important products in the economy of the area; it covers more than $50 \%$ of the agricultural area and contributes with the $7.2 \%$ of the national production. Ralstonia solanacearum bacterium is a causal agent of Moko disease of plantain and it is the most important phytosanitary problem, since $17 \%$ of this disease increment in number of affected municipalities, from 2002. In order to contribute to the management of this problem, it was explored the relationship between the incidence of the disease and variables related to physical and chemical properties of soil as well as the soil use and the altitudinal location. For this, 269 farms were studied, by using a stratified sampling design with proportional allocation to the sown area. Soil and leaf tissues were analyzed as well as the symptoms of disease. According to the model results, by ArcGis 9.3 (ESRI ${ }^{\circledR}$ ) software, the georeferenced points were interpolated using the technique of inverse distance weighted. The results showed that in $52 \%$ of the properties assessed, the disease was detected, and a significant positive correlation was found between the incidence of disease and saturated hydraulic conductivity and soil potassium; conversely, a negative and significant with altitude, foliar copper concentration and location of associated cultivation was also shown.

Additional key words: Ralstonia solanacearum, incidence, nutrition, potassium, copper.

Fecha de recepción: 06-07-2016 Aprobado para publicación: 24-11-2016

$\longrightarrow$

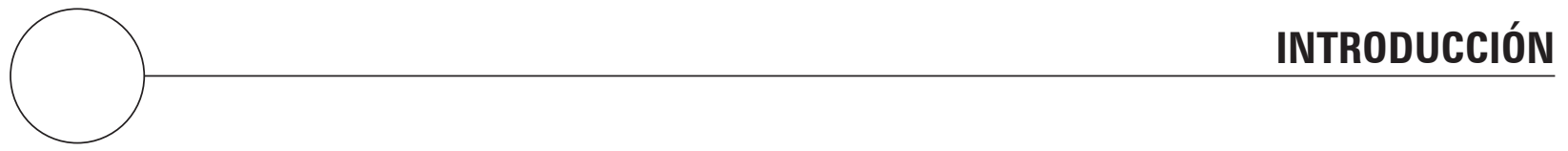

Entre los años 2005 y 2012 en Colombia el cultivo de plátano ocupó 355.602 ha, con una producción de 2.823 .825 t y un rendimiento de $7.937,75 \mathrm{~kg} \mathrm{ha}^{-1}$. Los departamentos de mayor participación fueron Arauca $(12,5 \%)$, Antioquia (9,5\%), Quindío (7,2\%), Meta $(7,1 \%)$ y Caldas $(6,8 \%)$ (MADR, 2013). En la región Quindiana, el plátano contribuye con más del $50 \%$ del área agrícola, 1997 fue el año más representativo con una participación de 64,5\%; para 1996 y 1997 contó con 45.953 y 39.013 ha, respectivamente; en 2011 el área disminuyó a 30.150 ha, con una producción de 301.879 t y rendimiento de $10,01 \mathrm{t} \mathrm{ha}^{-1}$ (EVAS, 2006; 2009; 2010; 2012).

A pesar de presentarse incremento del rendimiento, se ha registrado disminución en la producción y área cultivada, atribuida a problemas de tipo climático y sanitario. El cultivo de plátano Dominico Hartón, propio del departamento, presenta diversos problemas sanitarios, siendo la bacteria Ralstonia solanacearum Raza 2 la más limitante. Esta es considerada como el patógeno más agresivo de las musáceas en las regiones tropicales y subtropicales del mundo, y por su epidemiología, es una amenaza en países donde aún no se ha detectado (SENASICA, 2013). En áreas afectadas se generan pérdidas económicas por "no producir" durante los meses de cuarentena y resiembra; caso reportado en el Urabá Antioqueño, donde las pérdidas durante 35 años ascendieron a 1.328.763 cajas de banano (Castañeda y Espinosa, 2005).

La enfermedad puede presentarse en cualquier estado fisiológico de la planta, el ataque se desarrolla descendentemente a causa de daños mecánicos con herramienta infectada o por ataque de insectos al racimo, $\mathrm{y}$ ascendentemente cuando $R$. solanacearum penetra el sistema radical o pseudotallo por heridas; al ingresar causa el taponamiento de haces vasculares, induciendo debilitamiento por deficiencia de agua y nutrientes, causando finalmente la muerte (Hurtado, 2012).

La bacteria está reportada en 32 países de Asia, África, América del Norte, Central y Sur (EPPO, 2010). En Colombia, se reportó en 1954 en el departamento de Tolima, para 1962 se dispersó al Magdalena y en 1968 y 1970 a la zona bananera de Urabá y el eje cafetero, respectivamente (Granada, 2003). En el Quindío, se registró en los municipios de Armenia, Calarcá, Montenegro, La Tebaida y Quimbaya en 1998 (Merchán, 1998), en 2000 se reportó en 105 fincas, comprometiendo un área de 81,06 ha y 10 años después, el área aumentó a 418,21 ha (Vargas-Sánchez, 2000; 
Bejarano, 2010; ICA, 2010). Para 2010, en el Quindío se erradicaron 52.863 plantas y 17.621 focos (ICA, 2010); según el ICA, seccional Quindío, las pérdidas en producción ascendieron a 6.800 t y 3.000 millones de pesos (Bejarano, 2010).

La práctica de fertilización contribuye a disminuir la incidencia y severidad de enfermedades, por ende a la sostenibilidad de la producción y preservación del ambiente (Datnoff et al., 2006; Méndez y Viteri, 2007; Bolaños-Benavides, 2011; Ceballos et al., 2014; Viteri et al., 2012). Un desequilibrio nutricional puede inducir factores de resistencia o predisposición de las plantas al ataque de patógenos (Chaboussou, 1967; Gimenez y Rathjen, 2010; Riveros, 2010), de acuerdo con las interacciones entre estos (Eschen-Lippold et al., 2016). Adicionalmente, deficiencias nutricionales pueden aumentar la susceptibilidad (Velasco, 2000; Huber y Haneklaus, 2007) o incrementar la agresividad de las enfermedades (McMahon, 2012).

El análisis de problemas fitosanitarios en región demanda gran cantidad de recursos, por lo que mediante geoestadística y sistemas de información geográfica (SIG), se generan mapas temáticos sobre la distribución espacial y temporal de fenómenos naturales (Moral, 2004). Estas herramientas han sido útiles en estudios epidemiológicos y control de enfermedades (Nelson et al., 1999; Schroder, 2006), estimación espacial del ataque de patógenos (Lamsal, 2011; Parnell et al., 2011; Huang et al., 2012) y el análisis de condiciones agroecológicas que influyen en problemas fitosanitarios (Chica et al., 2011; Bautista et al., 2013).

Por lo anterior, esta investigación analizó la incidencia de la enfermedad del moko o maduraviche en el cultivo de plátano Dominico Hartón (Musa AAB Simmonds) en el departamento de Quindío y su relación con concentración foliar de nutrimentos, propiedades químicas y físicas del suelo, así como los usos de suelo y cotas altitudinales.

\section{MATERIALES Y MÉTODOS}

El estudio se llevó a cabo en 2013 en el departamento de Quindío, localizado en el centro occidente del país entre los $0^{\circ} 04^{\prime} 41^{\prime \prime}$ y $0^{\circ} 43^{\prime} 18^{\prime \prime}$ de latitud norte y los $75^{\circ} 23^{\prime} 41^{\prime \prime}$ y $75^{\circ} 53^{\prime} 56^{\prime \prime}$ de longitud oeste, con una superficie total de $1.845 \mathrm{~km}^{2}$ (IGAC, 1996). Para la selección de las fincas se utilizó el muestreo estratificado con afijación proporcional, los estratos correspondieron a los 12 municipios del departamento.
El marco muestral se definió a partir de los estudios de uso y cobertura de suelo a escala 1:10.000 (IGAC, 2010); mientras que el tamaño de muestra se calculó con la siguiente expresión (Scheaffer et al., 2007):

$$
n=\frac{\sum_{i=1} i N_{i}^{2} \frac{p i q i}{W i}}{N_{2} D+\sum_{i=1} i N_{1} p_{i} q_{i}}
$$

Donde: $\mathrm{n}=$ tamaño total de muestra; $\mathrm{Ni}=$ tamaño del estrato i-ésimo $(i=1,2,3) ; \mathrm{Wi}=$ proporción de área productora de plátano por estrato, con respecto al área total; pi = proporción estimada de afectación por moko para cada estrato fijada en el 10\%; qi=1- pi; $\mathrm{N}=$ tamaño total de la población; $\mathrm{D}=$ confiabilidad fijada en el $95 \%$ y un error de muestreo del $5 \%$.

El tamaño de muestra por estrato, se definió con afijación proporcional al tamaño del estrato, con la siguiente expresión:

$$
n i=n^{*} W i
$$

Donde: ni $=$ tamaño de la muestra por estrato i-ésimo $(i=1,2,3) ; \mathrm{n}=$ tamaño total de muestra; Wi = proporción de área productora de plátano por estrato.

De acuerdo con el número de fincas cultivadas con plátano en el departamento y la expresión empleada para determinar el tamaño de la muestra, se estableció el número de fincas a evaluar en los diferentes municipios (Tab. 1).

Tabla 1. Tamaño de la muestra por municipio en el departamento de Quindío.

\begin{tabular}{|l|c|c|}
\hline \multicolumn{1}{|c|}{ Municipio } & No. de fincas & Muestra \\
\hline Armenia & 373 & $60^{*}$ \\
\hline Buenavista & 142 & 13 \\
\hline Calarcá & 364 & 35 \\
\hline Circasia & 303 & 7 \\
\hline Córdoba & 210 & 10 \\
\hline Finlandia & 508 & 7 \\
\hline La Tebaida & 144 & 20 \\
\hline Montenegro & 572 & 60 \\
\hline Ouimbaya & 486 & 36 \\
\hline Salento & 66 & 7 \\
\hline Génova & 188 & 7 \\
\hline Pijao & 183 & 7 \\
\hline Total & 3539 & 269 \\
\hline
\end{tabular}

* Confiabilidad fijada en el $95 \%$ y un error de muestreo del $5 \%$. 
Las fincas seleccionadas en la muestra se georreferenciaron utilizando un GPS Gpsmap ${ }^{\circledR} 76 \mathrm{~S}$ (marca Garmin $\left.{ }^{\circledR}\right)$. La incidencia de la enfermedad en las fincas se identificó aleatoriamente, clasificándolas como sanas o enfermas, mediante evaluación de síntomas en campo y reportes del ICA, seccional Quindío (2012).

Se realizó análisis físico y químico de los suelos, y químico del tejido foliar en el Laboratorio de Suelos de Corpoica, Tibaitatá (Mosquera, Cundinamarca). Los resultados fueron sometidos a comparación de medias para dos grupos independientes (sano y enfermo) mediante la prueba $t$ de Student-Welch con un nivel de significancia $P \leq 0,05$.

Con el propósito de estimar la incidencia de la enfermedad en función de las variables a nivel del suelo y foliar, se ajustó un modelo de regresión logística utilizando el procedimiento LOGISTIC del software SAS; se seleccionó el modelo con variables significativas según la prueba $\mathrm{Ch}^{-2}$ de Wald, sobre la probabilidad de ocurrencia de esta enfermedad:

$P($ ocurrencia moko $)=\frac{1}{1+\mathrm{e}^{-\left[\left(\beta_{0}+\beta_{1} X_{1}+\beta_{2} X_{2}+\ldots+\beta_{p} X_{p}\right)\right]}}$

Donde: $\beta_{i}=$ parámetros estimados mediante el análisis de regresión logística, correspondientes a cada una de las variables explicativas o independientes; $\mathrm{X}_{\mathrm{i}}=$ variables explicativas (variables físicas y químicas del suelo, y químicas a nivel foliar); $i=1,2, \ldots$; $\mathrm{p}=$ número de variables independientes.

Finalmente, mediante herramientas geoestadísticas (Geostatical Analyst) del software ArcGIS 9.3 software (ESRI ${ }^{\circledR}$ ) y el método determinístico de interpolación espacial: Distancia Inversa Ponderada (IDW - Inverse Distance Weight), se representaron cartográficamente patrones de distribución de las variables más significativas del modelo sobre la probabilidad de incidencia de la enfermedad.

\section{RESULTADOS Y DISCUSIÓN}

\section{Incidencia de $R$. solanacearum}

El 52\% de las fincas se encontraron afectadas por la enfermedad, con incidencias de 77, 75 y $60 \%$ en los municipios de Armenia, Montenegro y La Tebaida, respectivamente; por otro lado, los municipios de
Quimbaya, Pijao, Calarcá, Circasia, Córdoba, Buenavista y Filandia presentaron valores inferiores al 50\%, mientras que Salento y Génova no reportaron la enfermedad (Fig. 1, izq.).

En este sentido, la distribución de la enfermedad en las fincas afectadas tiene influencia directa con la ubicación de los focos, ya que como lo reportan Tapiero et al. (2007), la enfermedad se desarrolla en zonas cercanas y lejanas a los focos, debido a la concentración del inóculo en suelo sin vegetación, arvenses hospederas asintomáticas, aguas de escorrentía y tejidos infectados (González et al., 2012).

La ubicación de las fincas respecto a la hidrología del departamento permitió observar mayor cantidad de predios enfermos en cercanías a fuentes hídricas. El papel del agua como reservorio de bacterias es esencial para su dispersión, ya que focos de un agente causal han tenido origen mediante la diseminación por aguas residuales o agroindustriales (Elphinstone, 1998; Steadman et al., 1975; Peñalver et al., 2009).

Para R. solanacearum Raza 2, se resalta la diseminación mediante canales de riego y drenaje, agua de escorrentía, ríos, arroyos o inundaciones por desborde de estos (Martínez y García, 2003; Tapiero et al., 2007), los cuales establecen la enfermedad en zonas sanas y su expansión por otros agentes diseminadores (Munar-Vivas et al., 2010; Álvarez et al., 2015) (Fig. 1, der.).

\section{Propiedades físicas y químicas de suelo, y concentración foliar de nutrimentos}

De acuerdo con la prueba $t$ de student para comparar fincas sanas y enfermas con respecto a las propiedades del suelo, se presentaron diferencias significativas $(P \leq 0,05)$ para $\mathrm{Cu}, \mathrm{Mn}, \mathrm{B}, \mathrm{Al}, \mathrm{Ca} / \mathrm{K}$ y altamente significativas $(P \leq 0,001)$ para $\mathrm{K}, \mathrm{Mg} / \mathrm{K}, \mathrm{Ca}+\mathrm{Mg} / \mathrm{K}, \mathrm{pH}$, $\mathrm{MO}, \mathrm{CIC}, \mathrm{CH}$ y AL $+\mathrm{H}$ (Tab. 2). Por otro lado, la concentración foliar nutrimentos presentó diferencias significativas $(P \leq 0,05)$ para $\mathrm{P}, \mathrm{S}, \mathrm{Cu}, \mathrm{Mn}$ y B (Tab. 3$)$.

El suelo de fincas reportadas como sanas presentó pH fuertemente ácido $(5,8)$, alta concentración de materia orgánica $(\mathrm{MO})$ y aluminio (Al), así como exceso de cobre $(\mathrm{Cu})$ y boro $(\mathrm{B})$, por otro lado, las fincas con plantas enfermas presentaron desbalance en las relaciones catiónicas del suelo y los valores de potasio (K) lo cual puede dificultar la asimilación de cationes bi-

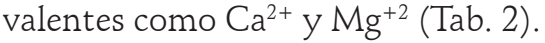




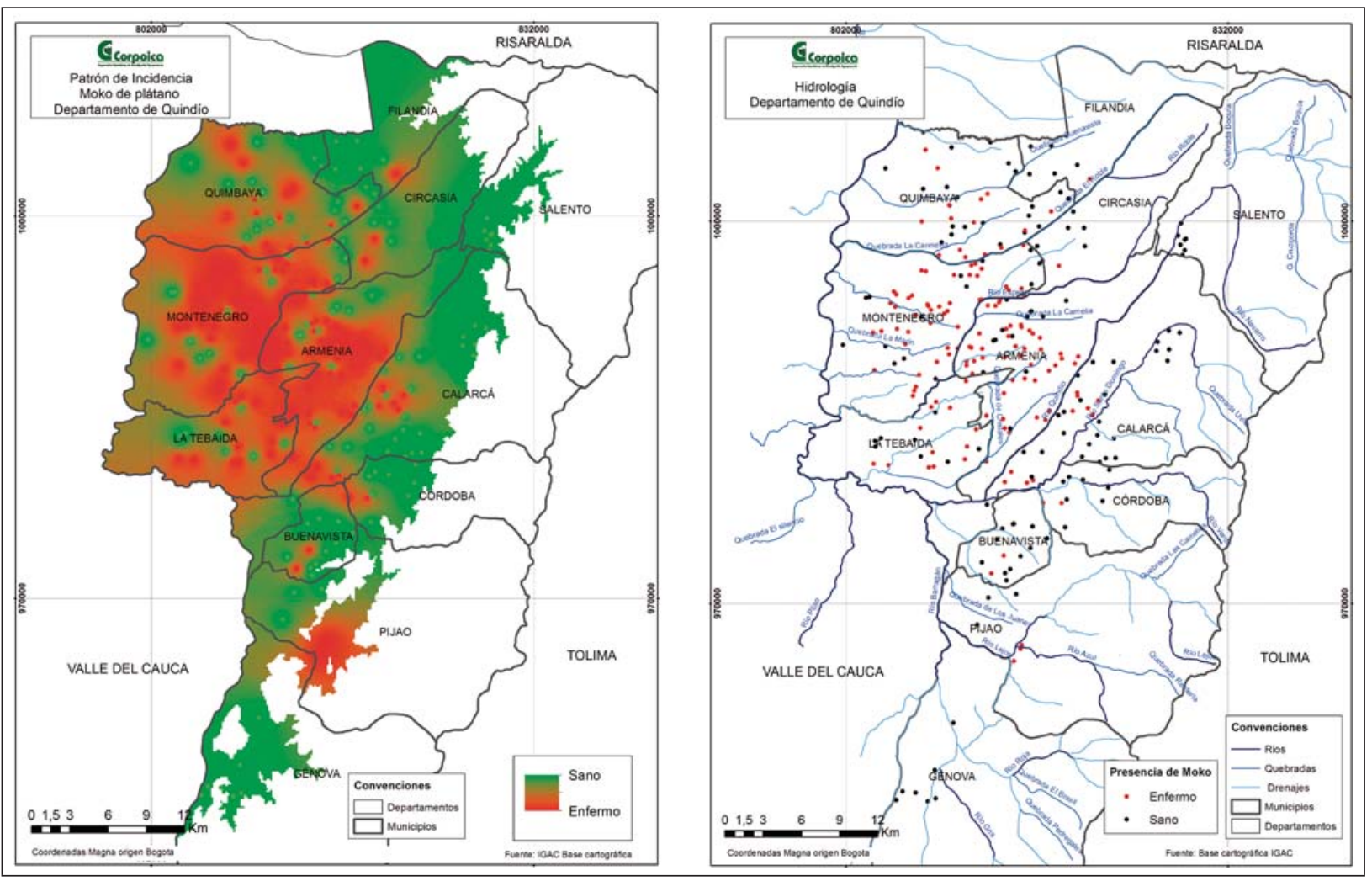

Figura 1. Patrón de incidencia de moko de plátano (izq.) y distribución de fincas sanas y enfermas en función de la higrología (der.) del departamento de Quindío. Escala 1:250.000. Fuente: Corpoica, 2016.

El suministro de calcio mejora la resistencia de las plantas a enfermedades causadas por hongos y nematodos (Agrios, 2005), esto mediante la inhibición de enzimas que degradan la superficie de los tejidos, adicionalmente, mayor contenido en paredes celulares aumenta la resistencia a patógenos causantes de marchitez vascular, al formar complejos de pectato-Ca que hacen resistentes las paredes del xilema (Waggoner y Dimond, 1955; Corden, 1965; Spann y Schumann, 2010). Por su parte el magnesio se considera como un activador de enzimas involucradas en la formación de especies reactivas de oxígeno (ROS) y un factor que disminuye la viabilidad de esporas de hongos cuando se encuentra alta relación con el calcio y potasio (Chuang, 1988).

Según los resultados de los análisis foliares, las plantas de las fincas sanas presentaron alta concentración en la mayoría de los elementos exceptuando potasio $(\mathrm{K})$, sodio $(\mathrm{Na})$, hierro $(\mathrm{Fe})$ y boro (B) (Munson, 1998) (Tab. 3).

De acuerdo con el análisis de regresión logística para establecer efectos de las variables del suelo y la concentración foliar de nutrimentos, así como la prueba $t$ realizada, se observó que la probabilidad de ocurrencia del moko de plátano está relacionada negativamente con la altitud (Alt) y la concentración foliar de cobre (Cufol); mientras que la conductividad hidráuli$\mathrm{ca}(\mathrm{CH})$ del suelo y la saturación de potasio en el suelo (Con $K$ ) se relacionaron positivamente:

$$
\begin{aligned}
P(\text { ocurrencia moko }) & =\frac{1}{1+\mathrm{e}-[(10.263-0.008 \text { Alt }+0.121 \mathrm{CH}-0.098 \text { Cufol }+7.648 \text { Con } k)]} \\
R^{2} & =38,8 \%
\end{aligned}
$$

La CH cuantifica el paso de agua en las primeras capas del suelo y describe la movilidad subsuperficial o subterránea (Forsythe, 1975; Montenegro y Malagón, 1990). Las fincas con mayores valores de CH se presentaron en los municipios de Armenia y Quimbaya (Fig. 2, izq.), coincidiendo con la mayor concentración de predios enfermos en cercanías a fuentes hídricas.

En este sentido, Tapiero et al. (2007) evaluando la persistencia de la bacteria $R$. solanacearum en suelo y aguas que conforman el flujo freático de cultivos de plátano del municipio de Fuente de Oro, Meta; mencionaron la influencia del movimiento de agua sobre la dispersión del patógeno en el área de estudio. 


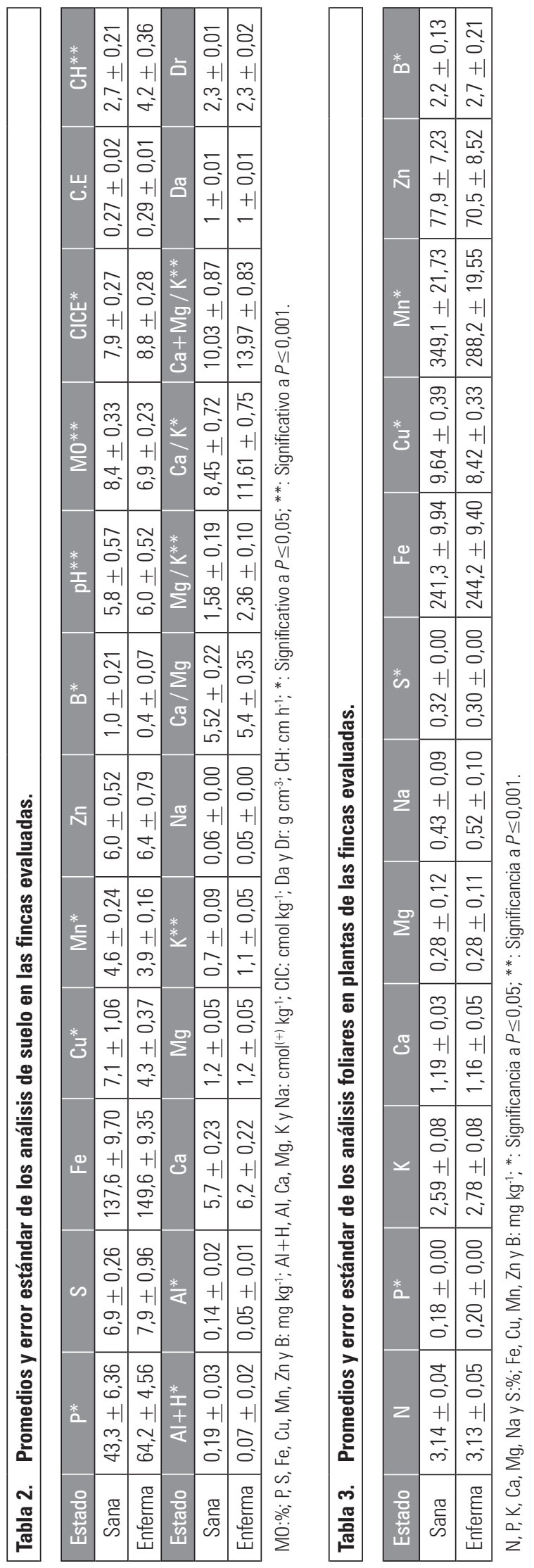

Para la concentración de potasio (Con K) en suelo, se observó que las fincas que presentaron mayor concentración de este elemento, reportan mayor incidencia de la enfermedad, la cual se concentra en los municipios de Quimbaya, La Tebaida, Armenia y Montenegro (Fig. 2, der.).

Conocidas las funciones metabólicas del K en la planta y su efecto sobre enfermedades (Datnoff et al., 2006), la incidencia de $R$. solanacearum y su relación con la saturación de K en el suelo puede ser interpretada como poca disponibilidad de este elemento o un proceso de fijación por parte del suelo. Este fenómeno se presenta cuando los iones de potasio se ubican en los sitios donde han sido adsorbidos, lo cual causa una contracción de las láminas de arcillas (Cox y Uribe, 1992) y se ve influenciada por factores térmicos, formas de $\mathrm{K}$ y condiciones de humedad (Huang y Jin, 1996; Conti, 2001; Navarro y Navarro, 2013). Los suelos del departamento de Quindío se clasifican dentro del orden Andisol (IGAC, 1995); de acuerdo a su mineralogía, fracción arcillosa y grado evolutivo, muestran un alto predominio de las arcillas neoformadas como caolinita y esmectitas (Sánchez y Rubiano, 2015).

Según un estudio mineralógico del departamento de Quindío (IGAC, 2004), los suelos con topografía de vertiente muestran contenidos superiores al $50 \%$ de caolinita y la abundancia de caolinita en sus suelos (68\%), se relaciona con una capacidad de intercambio canónico variable (CICV), superior a la CICE. Los suelos con cantidades considerables de arcillas caolinitas inducen baja disponibilidad de $\mathrm{K}$ hacia el sistema suelo-planta y presentan baja CIC, lo cual hace que el $\mathrm{K}$ intercambiable sea bajo (Jiménez et al., 2008); esta condición sugiere un suministro adicional del elemento (Navarro y Navarro, 2013), para lograr una mejor respuesta a nivel fisiológico y productivo frente a la fertilización con macronutrientes (Bolaños-Benavides et al., 2000).

El cobre foliar ( $\mathrm{Cufol}$ ) presentó un efecto significativo en la reducción de la probabilidad de ocurrencia de la enfermedad. El cobre está involucrado en procesos de transferencia de electrones y proteínas oxidativas, así como en la síntesis de ADN-ARN y procesos fotosintéticos (Marschner, 1995); este elemento tiene una tasa de absorción baja, se ve afectado principalmente por la especie de Cu (Kopsell y Kopsell, 2007) y su deficiencia ha sido relacionada con la disminución en la lignificación del xilema (Evans et al., 2006). 


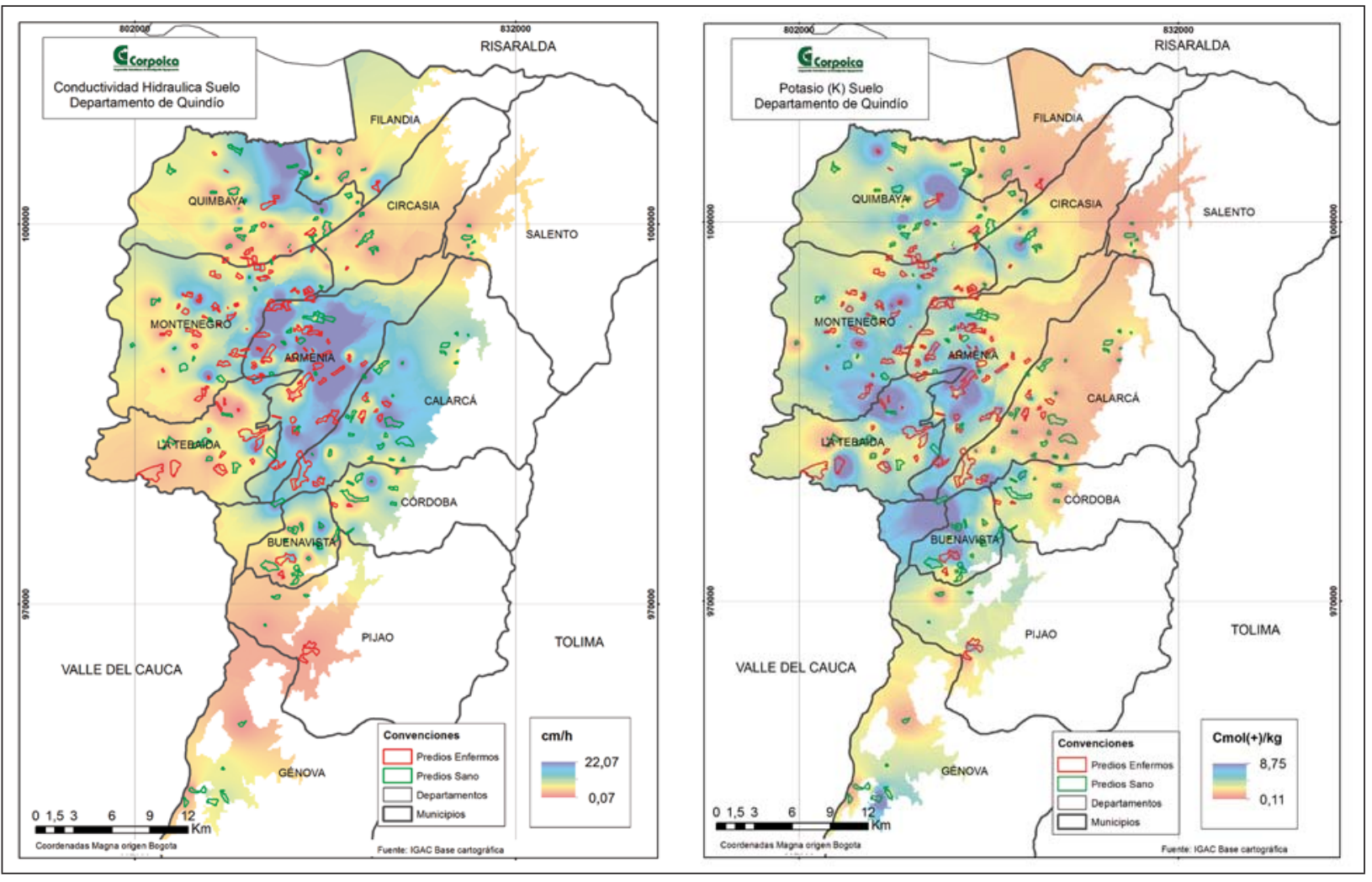

Figura 2. Distribución de fincas sanas y enfermas en función de la conductividad hidráulica (izq.) y la concentración de potasio en el suelo (der.) en el departamento de Quindío. Escala 1:250.000. Fuente: Corpoica, 2016.

El efecto del Cu sobre una enfermedad es atribuido a una toxicidad directa sobre los patógenos y al incremento de la resistencia del hospedero frente a estos, se considera un regulador esencial de enzimas involucradas en la producción de compuestos antimicrobianos, flavonoides, oxidación de aminoácidos, producción de especies reactivas de oxígeno y la regulación en la expresión de genes de resistencia (Evans et al., 2006). A este elemento se le han atribuido efectos sobre disminución de las poblaciones e incidencia de enfermedades causadas por bacterias (Medina-Urrutia y Stapleton, 1985; Kairu et al., 1991; Jones y Woltz, 1993; Datnoff et al., 2006).

En la presente investigación, los cultivos de plátano se ubicaron entre 1.064 y $1.819 \mathrm{msnm}$. La enfermedad se presentó en las fincas ubicadas a partir de 1.064 $\mathrm{msnm}$ mientras que las fincas en altitudes superiores a $1.676 \mathrm{msnm}$ fueron reportadas como libres de la enfermedad (Fig. 3, izq.). La relación de menor incidencia de la enfermedad respecto a la altitud, puede estar relacionada con la epidemiología del patógeno, ya que según Goszczynska et al. (2000) y SENASICA (2011),
R. solanacearum Raza 2, se desarrolla a temperaturas entre 35 y $37^{\circ} \mathrm{C}$.

Los resultados del presente estudio ubicaron las fincas enfermas en el paisaje de piedemonte, con clima medio muy húmedo a medio húmedo sobre un piso térmico templado. Por otro lado, las fincas sanas se ubican en el paisajes de montaña, con climas fríos muy húmedos a extremadamente fríos-húmedos, sobre pisos térmicos fríos a extremadamente fríos, los cuales presentan temperaturas promedio de 8 a $17^{\circ} \mathrm{C}$ (IGAC, 2014).

Se estableció que la baja probabilidad de ocurrencia de la enfermedad está relacionada significativamente con la cobertura de cultivos permanentes $(P e r)$ en comparación con cobertura de cultivos de plátano $(P l)$.

$$
\begin{aligned}
P(\text { ocurrencia moko }) & =\frac{1}{1+\mathrm{e}-[(0.121+0.111 \mathrm{Pl}-0.0131 \mathrm{Per})]} \\
R^{2} & =16,81 \%
\end{aligned}
$$

Esto podría ser entendido como menor probabilidad de ocurrencia de la enfermedad cuando se cuenta con 


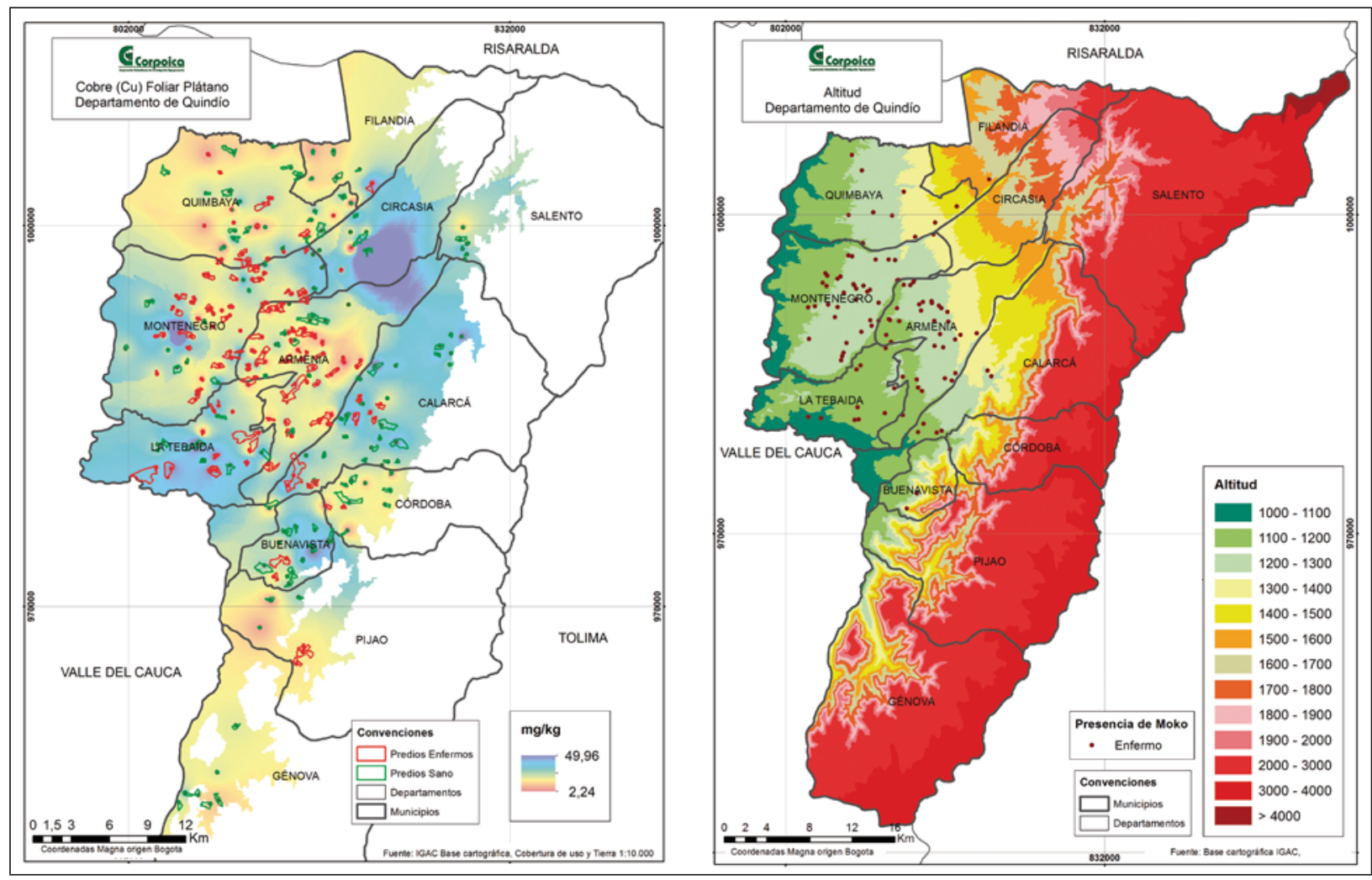

Figura 3. Distribución de las fincas sanas y enfermas en función del cobre foliar (izquierda - escala 1:250.000) y la altitud (derecha - escala 1:300.000) en el departamento de Quindío. Fuente: Corpoica, 2016.

diversificación en las fincas cultivadas con plátano. La combinación en un policultivo de especies susceptibles y resistentes a una enfermedad, reduce incidencias de microorganismos fitopatógenos, debido a la formación de barreras frente al movimiento de microorganismos, modificación de microclimas, rompimiento de ciclos biológicos de patógenos, efecto sobre la dinámica de las poblaciones de insectos vectores, supresión de arvenses hospederas, así como el efecto de plantas con propiedades alelopáticas (Gómez-Rodríguez y Zavaleta-Mejía, 2001; Arenas et al., 2005; Guzmán y Alonso, 2008).

\section{CONCLUSIONES}

En 2013 en el departamento de Quindío, 10 de los 12 municipios registraron la enfermedad del moko de plátano, los municipios de Salento y Génova se encontraron aparentemente libres de la bacteria.

El $52 \%$ de las fincas evaluadas en el departamento de Quindío registraron la enfermedad del moko de plátano, la cual mostró mayor incidencia y concentración entre los municipios de Armenia, Montenegro, La Tebaida y Quimbaya.

De acuerdo a la cartografía generada, se observaron fincas afectadas por moko de plátano en cercanías a fuentes hídricas del departamento de Quindío, factor que favorece la diseminación de la bacteria.

Se observó alta probabilidad de ocurrencia de la enfermedad en suelos con alta conductividad hidráulica y alta concentración de potasio; también se observó baja probabilidad de ocurrencia en plantas con alta concentración de cobre foliar y en fincas situadas a mayor altitud.

De acuerdo con la cobertura productiva del departamento de Quindío, se observó baja probabilidad de ocurrencia de la enfermedad en fincas con cultivos permanentes y alta probabilidad en áreas con plátano en monocultivo.

Se evidenció que las condiciones agroecológicas como las propiedades del suelo y la vegetación, tienen influencia sobre la presencia de la enfermedad; esto 
debe incluirse para planificar acciones culturales y sanitarias en el cultivo de plátano.

Se recomienda realizar estudios más detallados sobre las propiedades físicas y químicas de los suelos, así como la influencia de la nutrición en el desarrollo de la enfermedad del moko de plátano causada por $R$. solanacearum.

Se recomienda adelantar trabajos concernientes a la influencia de las condiciones agroecológicas y tipos de coberturas en las zonas productoras de plátano, y su relación con el desarrollo de la enfermedad del moko de plátano.

\section{AGRADECIMIENTOS}

Estos resultados hacen parte del proyecto "Estrategias para el manejo del moko en el departamento de Quindío. Fase I.", financiado por el Ministerio de Agricultura y Desarrollo Rural, y cuya ejecución estuvo a cargo de la Corporación Colombiana de Investigación Agropecuaria (Corpoica). Por su colaboración y cooperación se agradece especialmente al Instituto Colombiano Agropecuario (ICA), la Secretaría de Agricultura y Desarrollo Ambiental de Quindío, la Corporación Autónoma Regional de Quindío y las Umatas de los municipios de Quindío.

\section{REFERENCIAS BIBLIOGRÁFICAS}

Agrios, G. 2005. Plant pathology. $5^{\text {th }}$ ed. Elsevier Academic Press, Amsterdam, The Netherlands.

Álvarez, E., A. Pantoja, L. Gañan y G. Ceballos. 2015. Current status of Moko disease and Black Sigatoka in Latin America and the Caribbean, and options of managing them. CIAT Publication No. 404. Centro Internacional de Agricultura Tropical (CIAT), Cali, Colombia.

Arenas, A., D. López, E. Álvarez, G. Llano y J. Loke. 2005. Efecto de prácticas ecológicas sobre la población de Ralstonia solanacearum Smith, causante de moko de plátano. Rev. Fitopatol. Colomb. 28(2), 76-80.

Bautista, L., J. Cardona y A. Soto, 2013. Distribución espacial de Collaria scenica (Hemiptera: Miridae) y Hortensia similis (Hemiptera: Cicallidae) en valles andinos. Boletín Científico Centro de Museos: Museos de Historia Natural 17(2), 75- 84.

Bejarano, A. 2010. El moko en el plátano en el departamento del Quindío. Últimos avances en la tecnología del cultivo del plátano en Colombia. Corporación
Colombiana de Investigación agropecuaria (Corpoica), C.I. La Libertad, Villavicencio, Colombia.

Bolaños-Benavides, M., J. Valencia-Montoya y H. Morales-Osorno. 2000. Importancia de la nutrición integrada en el cultivo de plátano (Musa AAB Simmonds). pp. 24. En: Resúmenes 14 Reunión de la Asociación para la Cooperación de Investigación de Banano en el Caribe y en América Tropical. ACORRBAT, San Juan, Puerto Rico.

Bolaños-Benavides. M. 2011. Informe técnico final del proyecto Mejoramiento de la sanidad y competitividad del cultivo del plátano, mediante el desarrollo de nuevas estrategias del manejo del suelo y la nutrición. Corporación Colombiana de Investigación Agropecuaria (Corpoica), C.I. Palmira, Colombia.

Castañeda, D. y J. Espinosa. 2005. Comportamiento e impacto de la enfermedad de moko en la zona de Urabá (Colombia), en las últimas tres décadas y media y propuesta de un índice de riesgo de la enfermedad. Rev. Fac. Nal. Agron. Medellín 58(1), 2587-2599.

Ceballos, G., E. Álvarez y M.M. Bolaños. 2014. Reducción de poblaciones de Ralstonia solanacearum raza 2 (Smith) en plátano (Musa AAB Simmonds) con aplicación de extractos de Trichoderma sp. (Alexopoulus y Mims) y bacterias antagonistas. Acta Agron. 63(1), 1-8. Doi: 10.15446/acag.v63n1.43121

Chaboussou, F. 1967. La trophobiose ou les rapports nutritinnels entre la Plante-hôte et ses parasites. Ann. Soc. Ent. Fr. 3(3), 797-809.

Chica, P., G. Cruz y O. Guzmán-Piedrahita. 2011. Propuesta metodológica para la evaluación de biodiversidad de nematodos en dos ecosistemas naturales. Rev. Agron. Univ. Caldas 19(2), 7-18.

Chuang, Y. 1988. Studies on the soils suppressive to banana Fusarium wilt ii. Nature of suppression to Race 4 of Fusarium oxysporum fs. cubense in Taiwan soils. Plant Protection 30(2), 125-134.

Conti, M. 2001. Disponibilidad de potasio, aspectos relacionados a la dinámica de liberación y renovación de la solución del suelo. pp. 13-59. En: Memorias El potasio en Sistemas Agrícolas Argentinos. $1^{\circ}$ Simposio FAUBAIPI-INTA. Buenos Aires.

Corden, M. 1965. Influence of calcium nutrition on Fusarium wilt of Tomato and polygalacturonase activity. Phytopathol. 55(2), 22-24.

Cox, F. y E. Uribe. 1992. Potassium in two humid tropical ultisol under a corn and soybean cropping system. Dinamics Agron. 84, 485-489. Doi: 10.2134/agronj1992. $00021962008400030024 x$

Datnoff, L.E., W. Elmer y D. Huber, D. (eds.) 2006. Mineral nutrition and plant disease. APS Press, St. Paul, MN.

Elphinstone, J. 1998. The current bacterial wilt situation: a global overiew. pp. 9-28. En: Allen, P., A. Prior y C. Hayward (eds). 2005. Bacterial wilt: The disease and 
the Ralstonia solanacearum species complex. APS Press, St. Paul, MN.

Eschen-Lippold, L., X. Jiang, J. Mitch Elmore, D. Mackey, L. Shan, G. Coaker, D. Scheely y J. Lee. 2016. Bacterial AvrRpT2-Like cysteine proteases block activation of the Arabidopsis Mitogen-Activated protein Kinases, MPK4 and MPK11. Plant Physiol. 171(3), 2223- 2238. Doi: $10.1104 /$ pp.16.00336

EPPO. 2010. Quarantine procedure No. 26. Ralstonia solanacearum inspection and test methods. European and Mediterranean Plant Protection Organization. EPPO Bull. 20, 255-262. Doi: 10.1111/j.1365-2338.1990. tb01205.x

Evans, I., E. Solberg y D. Huber. 2006. Copper and plant disease. pp. 177-188. En: Datnoff, L.E., W. Elmer y D. Huber (eds.) Mineral nutrition and plant disease. APS Press, St. Paul, MN.

EVAS (Evaluaciones Agropecuarias Departamento del Quindío). 2006, 2009, 2010, 2012. Informes Agropecuario años 2005, 2008, 2009 y 2010/2011. Armenia, Colombia.

Forsythe, W. 1975. Física de suelos: Manual de laboratorio. $2^{a}$ ed. San José, Costa Rica.

Gimenez, S. y J. Rathjen. 2010. The case for the defense: plants versus Pseudomonas syringae. Microbes Infection 12, 428-437. Doi: 10.1016/j.micinf.2010.03.002

Gómez-Rodríguez, O. y E. Zavaleta-Mejía. 2001. La asociación de cultivos una estrategia más para el manejo de enfermedades, en particular con Tagetes spp. Rev. Mex. Fitopatol. 19, 94-99.

González, C., E. Arévalo, A. Díaz, J. Galindo, M. Rivero y M. Guerrero. 2012. Manejo fitosanitario del cultivo del plátano (Musa spp.); medidas para la temporada invernal. Instituto Colombiano Agropecuario (ICA), Bogotá.

Granada, A. 2003. Manejo integrado del Moko (Ralstonia solanacearum Raza 2) en cultivos de banano y plátano. Boletín Técnico Cenibanano. Augura 2, 9-13.

Guzmán, G. y M. Alonso. 2008. Buenas prácticas en producción ecológica asociaciones y rotaciones. Ministerio de Medio Ambiente y Medio Rural y Marino, Madrid.

Huang, S. y Y. Jin. 1996. Potassium fixation in different soils from north China. Plant Nutr. Fert. Sci. 2(2), 131-138.

Huang, W., J. Luo, J. Zhang, J. Zhao, C. Zhao, J. Wang, G. Yang, M. Huang, L. Huang y S. Du. 2012. Crop disease and pest monitoring by remote sensing. pp. 32-73. En: Escalante-Ramirez, B. (ed). 2012. Remote sensing - applications. Intech. Doi: 10.5772/35204

Huber, D. y S. Haneklaus. 2007. Managing nutrition to control plant disease. Landbauforsch. Volkenrode 57(4), 313-322.
Hurtado, R. 2012. Caracterización de síntomas de la enfermedad de Moko en invernadero y campo cuando se simulan labores que causen heridas en plantas de banano y plátano. Boletín Técnico Centro de Investigación del Banano - Cenibanano No. 4.

ICA. 2012. Base de datos de vigilancia fitosanitaria de fincas de plátano afectadas por Ralstonia solanacearum. Instituto Colombiano Agropecuario, Seccional Quindío, Armenia, Colombia.

ICA. 2010. Informe de gestión. Instituto Colombiano Agropecuario, Tibaitatá, Mosquera, Colombia.

IGAC. 1995. Suelos de Colombia: Origen, evolución, clasificación, distribución y uso. Instituto Geográfico Agustín Codazzi, Bogotá.

IGAC. 1996. Suelos del Departamento del Quindío. Instituto Geográfico Agustín Codazzi, Bogotá.

IGAC. 2004. Propiedades de los suelos. pp. 63-90. En: Estudio general de suelos y zonificación de tierras del departamento de Quindío. 2a ed. Instituto Geográfico Agustín Codazzi, Bogotá.

IGAC. 2010. Coberturas y usos de la tierra del departamento del Quindío. Instituto Geográfico Agustín Codazzi, Bogotá.

IGAC. 2014. Estudio semidetallado de suelos y zonificación de tierras. Departamento del Quindío. Instituto Geográfico Agustín Codazzi, Bogotá.

Jiménez, F., L. Rojas y M. Henao. 2008. Dinámica y disponibilidad de potasio en andisoles e inceptisoles dedicados al cultivo de la papa en el altiplano cundiboyacense. Suelos Ecuat. 38(1), 1-8.

Jones, J. y S. Woltz. 1993. The effect of selected copper bactericides on population dynamics of Xanthomonas campestris pv. vesicatoria in tomato leaflets. Proc. Fla. State Hort. Soc. 106, 160-163.

Kairu, G., C. Nyangena y J. Muthamia. 1991. The performance of copper-based bactericides in the control of bacterial blight of coffee and coffee berry disease in Kenya. Trop. Pest Manage. 37(1), 1-5. Doi: 10.1080/09670879109371526

Kopsell, D. y D. Kopsell. 2007. Copper. pp. 293-323. En: Barker, A. y D. Pilbeam. Handbook of plant nutrition. Taylor and Francis, New York, NY.

Lamsal, S., R. Cobb, H. Cushman, O. Meng, D. Rizzo y R. Meentemeyer. 2011. Spatial estimation of the density and carbon content of host populations for Phytophthora ramorum in California and Oregon. For. Ecol. Manag. 262, 989-998. Doi: 10.1016/j.foreco.2011.05.033

MADR 2013. Anuario estadístico del sector agropecuario 2012. Resultados evaluaciones agropecuarias municipales. Ministerio de Agricultura y Desarrollo Rural, Bogotá.

Marschner, H. 1995. Mineral nutrition of higher plants. $2^{\text {nd }}$ ed. Academic Press, London. 
Martínez, G. y R. García. 2003. Manejo de la enfermedad del Moko o Ereke en el cultivo del plátano para la Orinoquía colombiana. Boletín divulgativo No. 9. Corporación Colombiana de Investigación Agropecuaria (Corpoica), Tibaitatá, Mosquera, Colombia.

McMahon, P. 2012. Effect of nutrition and soil function on pathogens of tropical tree crops. En: Cumagun (ed.). Plant pathology. Doi: 10.5772/32490

Medina-Urrutia, V. y J. Stapleton. 1985. Control of mexican lime bacteriosis with copper-based products. Proc. Fla. State Hort. Soc. 98, 22-25.

Méndez, M. y S. Viteri. 2007. Alternativas de biofertilización para la producción sostenible de cebolla de bulbo (Alium cepa) en Cucaita, Boyacá. Agron. Colomb. 25(2), 168-175.

Merchán, V. 1998. Manejo de problemas fitosanitarios del cultivo del plátano en la zona central cafetera. Memorias Seminario Internacional sobre producción de plátano. Armenia, Quindío, Colombia.

Montenegro, H. y D. Malagón. 1990. Propiedades físicas de los suelos. Instituto Geográfico Agustín Codazzi, Bogotá.

Moral, F. 2004. Aplicación de la geoestadística en las ciencias ambientales. Rev. Ecosistemas 13(1), 78-79.

Munar-Vivas, O., J. Morales-Osorio y D. Castañeda-Sánchez. 2010. Use of field-integrated information in GIS-based maps to evaluate Moko disease (Ralstonia solanacearum) in banana growing farms in Colombia. Crop Protection. 29, 936-941. Doi: 10.1016/j. cropro.2010.04.021

Munson, R. 1998. Principles of plant analysis. pp. 1-24. En: Kalra, Y. (ed). 1998. Handbook of methods for plant analysis. CRC Press, Boca Raton, FL.

Navarro, G. y S. Navarro. 2013. Química agrícola: Química del suelo y de los nutrientes esenciales para las plantas. Mundi-Prensa, Madrid.

Nelson, M., T. Orum y R. Jaime-García. 1999. Applications of geographic information systems and geostatistics in plant disease epidemiology and management. Plant Dis. 38(4), 308-319.

Parnell, S., R. Gottwald, S. Irey, W. Luo y F. van den Bosch. 2011. A stochastic optimization method to estimate the spatial distribution of a pathogen from a sample. Phytopathol. 101, 1184-1190. Doi: 10.1094/ PHYTO-11-10-0331

Peñalver, R., P. Llop, E. Marco-Noales y L.M. Milagros. 2009. Especial grupo de microbiología de plantas, bacterias fitopatógenas: i̇s posible su prevención?. Sociedad Española de Microbiología, Madrid.
Riveros, A. 2010. Inducción de resistencia en plantas. Interacción: planta-patógeno. Instituto Interamericano de Cooperación para la Agricultura (IICA), Bogotá.

Sánchez, J. y Y. Rubiano. 2015. Procesos específicos de formación en Andisoles, Alfisoles y Ultisoles en Colombia. Rev. EIA 12(2), 85-97. Doi: 10.14508/reia.2015.11. E2.85-97

Schroder, W. 2006. GIS, geostatistics, metadata banking, and tree-based models for data analysis and mapping in environmental monitoring and epidemiology. International J. Med. Microbiol. 296(1), 23-36. Doi: 10.1016/j.ijmm.2006.02.015

SENASICA. 2011, 2013. Servicio Nacional de Sanidad, Inocuidad y Calidad Agroalimentaria. Ficha técnica Moko del plátano Ralstonia solanacearum Raza 2. Secretaría de Agricultura, Ganadería, Desarrollo Rural, Pesca y Alimentación, México, D.F.

Spann, T. y A. Schumann. 2010. Mineral nutrition contributes to plant disease and pest resistance. The Horticultural Sciences Department, Florida Cooperative Extension Service, Institute of Food and Agricultural Sciences, University of Florida. En: https://edis.ifas. ufl.edu/hs1181; consulta: febrero de 2016.

Steadman, J., C. Maier, H. Schwartz y E. Kerr. 1975. Pollution of surface irrigation waters by plant pathogenic organisms. JAWRA 11(4), 796-804. Doi: 10.1111/ j.1752-1688.1975.tb00731.x

Tapiero, A., A. Morales y S. Rodríguez. 2007. Dispersión de Ralstonia solanacearum en suelos cultivados con plátano en el Piedemonte Llanero. Cienc. Tecnol. Agropecu. 8(1), 52-60. Doi: 10.21930/rcta.vol8_num1_art:83

Vargas-Sánchez, J. 2001. El moko del plátano y banano y su manejo institucional por parte del ICA en el Quindío. pp. 31-35. En: Memorias Seminario-taller Manejo Integrado de Sigatokas, Moko y Picudo negro del Plátano en el Eje Cafetero. Manizales, Colombia.

Velasco, V. 2000. Role of mineral nutrition on plant disease tolerance. Terra 17(3), 193-200.

Viteri, S., M. Méndez y J. Villamil. 2012. Verification of alternatives for sustainsable onion production (Allium cepa L.) in Cucaita, Boyacá. Agron. Colomb. 30(1), 124-132.

Waggoner, P. y A. Dimond. 1955. Production and role of extracellular pectic enzymes of Fusarium oxysporum fs. Lycopersici. Phytopathol. 45, 79-87. 